\title{
MTV Brasil e o Ocaso do Fluxo
}

\section{Felipe Muanis}

Doutor em Comunicação Social pela UFMG. Professor de televisão e mídias digitais do Departamento de Cinema e Vídeo e do Programa de Pós-graduação em Comunicação da Universidade Federal Fluminense e Coordenador do ENTELAS: grupo de pesquisa em televisão, teoria, imagem e recepção. Email: felipemuanis@id.uff.br.
${ }^{1} \mathrm{~A}$ emissora, hoje, passou a ser apenas MTV, eliminando "Brasil" do nome.
Resumo: Em 2013, acabou a experiência da MTV Brasil, que deu lugar a uma nova MTV, rompendo radicalmente com o modelo anterior e aproximando-se do canal norte-americano. A partir de uma análise do canal extinto, pretende-se discutir neste artigo como a MTV Brasil evidencia questões teóricas da televisão, em especial a noção de fluxo de Raymond Williams e as teorias de paleo e neotelevisão. Nesse contexto, seria a MTV, em seu início, a emissora que mais se aproximaria das propostas de fluxo teorizadas, tornando-se uma flow television.

Palavras-Chave: Fluxo; Neotelevisão; Segmentação; Flow Television.

\section{Title: MTV Brasil and the Flow sinking}

Abstract: In 2013 ended the MTV Brasil experience, which gave rise to a new MTV that broke radically with the previous model, approaching the North American channel. From an analysis of the extinct channel, we intend to discuss in this article as MTV Brasil highlights theoretical issues of television, in particular Raymond Williams notion of flow and theories of paleo and neotelevision. In this context, would be to MTV, at its beginning, the station that you feel most closely the theorized flow, making it a flow channel.

Keywords: Flow; Neotelevision; Segmentation; Flow Television.

\begin{abstract}
A nova MTV que viria e que veio é uma nova MTV mesmo, é outro canal, completamente diferente, que rompeu oficialmente com o modelo anterior. Com certa razão, eles são mais modernos do que a gente; a gente envelheceu no final.
\end{abstract}

Zico Goes (2013)

No dia 30 de setembro de 2013, saiu do ar, depois de 20 anos, o primeiro canal segmentado da TV brasileira, a franquia de um canal norte-americano com versões em alguns países, a Music Television. Durante esse tempo, a MTV Brasil, gerenciada pela Televisão Abril, consolidou-se como uma experiência única no país, modificando o cenário do mercado fonográfico, das produtoras independentes de audiovisual, do comportamento jovem e da estética televisiva, influenciando até mesmo o cinema brasileiro, para desespero de muitos. Não foram, contudo, essas as únicas contribuições da antiga MTV Brasil, que cedeu lugar a uma nova emissora ${ }^{1}$, dessa vez gerenciada por quem detém seus direitos, a norte-americana Viacom. A experiência da MTV Brasil desde 1990 e seu fim no último ano marcam de modo indelével a experimentação na história da televisão 
brasileira, situando-a ao lado de emissoras fundamentais no país, como a Rede Tupi ou a Excelsior, por suas inúmeras inovações, mas especialmente por suscitar reflexões no campo teórico da televisão.

A MTV surgiu nos Estados Unidos em agosto de 1981 como uma emissora segmentada de narrowcast - via cabo ou satélite - , com o intuito de exibir videoclipes de bandas e músicos do gênero de rock n'roll. De acordo com Zico

${ }^{2}$ Em conferência no Festival Internacional de Televisão, em 14 de novembro de 2013, no Oi Futuro, Rio de Janeiro.
Goes $^{2}$, ex-diretor de Programação da MTV Brasil, a MTV começou nos Estados Unidos como "um canal que compilava videoclipes, o canal mais barato que poderia existir na face da Terra. [...] Os donos da MTV praticamente não investiram quase nada" (GOES, 2013). A MTV norte-americana produzia apenas os promos, vinhetas e artbreaks, sendo os videoclipes gratuitos, pois eram produzidos e enviados pelas próprias gravadoras. De acordo com Goes, à época, era muito fácil ter um canal de televisão nos Estados Unidos; bastava apenas alguém que o distribuísse.

A partir de então, dois movimentos da emissora foram importantes para pensar as transformações da MTV: o primeiro, o franqueamento do canal para inúmeros países, totalizando hoje 52 emissoras espalhadas por todos os continentes, entre franquias em funcionamento e não mais operantes. $O$ segundo fator relevante foi a mudança no canal matriz nos Estados Unidos, onde a MTV deixou de ser um canal só de videoclipes para agregar outros formatos de programas e, consequentemente, abrir outros canais que mantinham a proposta original, como o VH1 (1985) e a MTV 2 (1996).

A primeira proposta de trazer a MTV para o Brasil, ainda na década de 1980, surgiu na tentativa de uma associação entre Walter Clark, a Rede Manchete e a produtora paulista Olhar Eletrônico, de Fernando Meirelles. Apesar de o projeto não ter prosperado, a união de pessoas e empresas que são sinônimo de inovação na história da televisão brasileira, com o objetivo de implementar uma franquia da MTV, mostra o quanto esse canal se diferenciava dos demais. Mas foi apenas em 1990 que a MTV surgiu no Brasil por intermédio de outras pessoas, mais por uma necessidade do que por um projeto bem-elaborado. O Grupo Abril tinha obtido uma concessão de canal de TV aberta em 1985, e com um ano apenas para seu vencimento viu-se obrigado a colocar um canal de televisão no ar. A MTV aparece, então, como uma escolha óbvia por sua informalidade, a possibilidade de custos mais baixos de implementação e de improvisação.

Nesse sentido, destaca-se uma singularidade da franquia brasileira com relação às demais: a versão brasileira do canal foi a primeira de sinal aberto em todo o mundo. Além disso, é relevante ressaltar que a MTV não era um canal com características de um canal generalista e que pudesse ser absorvido pelo broadcasting tradicional. Com uma estrutura inicial baseada na exibição de videoclipes e vinhetas, voltada para o público jovem, a MTV Brasil era um canal segmentado em meio ao espectro de canais generalistas. É importante lembrar que, no início da década de 1990, tanto a Rede Manchete quanto a Rede Bandeirantes buscaram imprimir identidades parcialmente segmentadas, a primeira mais voltada para o jornalismo, e a segunda, para a programação esportiva. Mesmo em seu início na década de 1960, a experiência inicial da TV Bandeirantes era voltada para uma programação elitista e cultural. Apesar de tais características, tanto a Rede Manchete quanto a Rede Bandeirantes nunca deixaram de ser canais generalistas.

O surgimento da MTV Brasil como canal aberto não era, portanto, irrelevante. Como recorda oportunamente Luíza Lusvarghi (2007), a televisão segmentada no Brasil surge apenas um ano depois da MTV Brasil e pelas mãos do próprio Grupo Abril, que passa a comercializar a distribuidora de canais por assinatura da TVA e por meio da NET, então empresa das Organizações Globo. Desse modo, o simples fato de haver uma emissora segmentada em meio a canais generalistas, em um país que ainda não conhecia e nem tinha o hábito de consumir TV segmentada, já fazia da MTV Brasil um canal com uma lógica distinta da dos demais. Ainda assim, era 
3John Caldwell considera que a TV trabalha com duas modalidades de imagem: uma de intensidade zero, planar, sem contraste, com pouca variedades de pontos de vista e a televisão estilo ou cinemática que se aproxima da imagem cinematográfica com contraste, maior variedade de pontos de vista e profundidade. Para mais detalhes sobre a imagem de intensidade zero e a televisualidade, ver Caldwell (1995).

${ }^{4}$ Rogério Galo, diretor musical da MTV Brasil. [N.A.] um canal realmente segmentado. Por estar disponível no espectro, não costumava atrair um público que não fosse seu preferencial - o jovem entre 18 e 29 anos.

No campo técnico, o audiovisual começava a migrar para a imagem digital e suas possibilidades, inicialmente concentradas na edição não linear, mas não ainda na captação. A MTV Brasil se estruturou como a primeira emissora brasileira a basear toda a sua finalização no processo digital não linear, o que lhe conferiu facilidade de explorar novas possibilidades estéticas e discursivas em seus programas. Ainda que a emissora produzisse inicialmente apenas as cabeças dos programas, apresentados pelos VJs, e alguns poucos programas de cunho informativo-documental, eles não produziam os videoclipes que exibiam, o que diminuía significativamente os custos do canal. Normalmente, os videoclipes, peças promocionais de artistas do mercado fonográfico, eram distribuídos pelas próprias gravadoras para o canal, ou feitos de forma artesanal por artistas independentes que queriam se promover e ganhar visibilidade. Na época, a internet apenas engatinhava e ainda estava longe de plataformas de vídeo como o Vimeo (2004) ou o YouTube (2005), hoje populares.

Sem querer entrar na discussão dos primórdios do videoclipe como formato ou programa - uns afirmam que começou com os Beatles, e outros, com o videoclipe de Bohemian Rhapsody da banda Queen -, no Brasil os videoclipes surgiram como atrações do programa dominical Fantástico, exibido pela Rede Globo, mais precisamente em 29 de junho de 1975, com a exibição de América do Sul, música de Paulo Machado interpretada por Ney Matogrosso. Gravados em vídeo, os videoclipes produzidos pelo Fantástico normalmente passavam uma única vez e não primavam por uma qualidade de imagem cinemática, mantendo as características de uma imagem de intensidade zero ${ }^{3}$. A MTV Brasil surge, portanto, em um país com uma cultura audiovisual que não tinha desenvoltura com o produto videoclipe. Mesmo havendo demanda do novo canal por essas produções nacionais, o conteúdo era pouco e pobre, e, apesar da proposta da emissora de ter produtos nacionais, de acordo com Lusvarghi (2007: 52), “já falavam em 70\% de importação" de clipes estrangeiros. De acordo com a autora:

\begin{abstract}
A discussão sobre a qualidade levou a uma polêmica, pois a maior parte dos videoclipes brasileiros era gravada para ser exibida no Fantástico [...] e classificados por Galo ${ }^{4}$ como os piores, por não apresentarem técnica de cinema, o que levou Boni [...], diretor de alguns clipes e à época vicepresidente da TV Globo, a defender-se publicamente, alegando que a questão não era gravar em película, videoteipe ou captação gráfica, mas sim transmitir uma ideia. (LUSVARGHI, 2007: 52)
\end{abstract}

A partir da falta de material nacional de qualidade, a MTV Brasil resolveu investir na produção de 20 videoclipes de músicos brasileiros consagrados, como Marina Lima - o primeiro videoclipe a ser exibido no canal, uma versão de "Garota de Ipanema" - Marisa Monte, Caetano Veloso, Paralamas do Sucesso, entre outros, todos feitos em película e por jovens diretores de produtoras independentes.

O impacto, não apenas do início das atividades da MTV Brasil, mas de sua demanda por videoclipes de qualidade no mercado nacional, teve um efeito fundamental não apenas para a emissora, mas para o desenvolvimento do audiovisual no país. É necessário, contudo, contextualizar o momento político da época. A Embrafilme tinha sido extinta pelo governo Fernando Collor em março daquele mesmo ano, sem criar uma política para o setor audiovisual para substituíla, o que resultou na paralisação do mercado cinematográfico e no desemprego de inúmeros técnicos de cinema. A televisão não tinha capacidade para absorver toda essa mão de obra, pois já tinha sua própria estrutura e monopolizava, como faz até hoje, toda a sua produção. Então, a demanda por videoclipes filmados em película surge em um momento oportuno, em que só se poderia fazer audiovisual 
dentro de uma televisão ou produzindo comerciais e videoclipes em produtoras independentes. Apesar da indigente política cultural do período, a adversidade favoreceu o surgimento de produtoras independentes com uma nova geração de realizadores que esperavam ganhar visibilidade e dinheiro por meio de comerciais e videoclipes para, no futuro, chegarem ao cinema. Foi o que aconteceu de fato com a Conspiração Filmes, a Vídeo Filmes, a TV Zero no Rio de Janeiro, entre outras produtoras no país. Todos os seus diretores trouxeram novas ideias para seus trabalhos, além de se influenciarem por uma estética mundializada, que dialogava com a história do cinema, as histórias em quadrinhos, o documentário, o videoclipe e a publicidade, misturando linguagens, suportes, texturas e técnicas. Essa formação específica em um mercado que lutava para sobreviver preparou uma nova geração de realizadores que trouxeram novos referenciais e estéticas para o audiovisual brasileiro. Essa lógica também se repetiu com animadores e designers, que passaram a ter nas criativas e inovadoras vinhetas institucionais da MTV Brasil uma possibilidade de divulgar suas criações. E enquanto o canal priorizou os videoclipes e as vinhetas em sua programação, tanto essas estéticas quanto seus realizadores e produtoras puderam aquecer o mercado, ainda que na maioria das vezes centralizado na região Sudeste do país.

Ainda que tais características contextuais, técnicas e históricas realcem a importância da MTV Brasil para a televisão brasileira, é sobretudo na discussão da recepção que é possível observar desdobramentos em sua história que podem aludir a discussões teóricas importantes no campo dos estudos de televisão.

\section{Music ou flow television?}

Em 1974, Raymond Williams publicou um livro que se tornou referência nos estudos de televisão. Em Television as cultural form, ele conceitua o fluxo televisivo. De acordo com o autor, a quantidade de programas em sequência criava uma sensação de não se ver mais um programa, como no início da televisão, mas um fluxo contínuo de imagens e sons. Williams escreve que, antes da televisão, espetáculos tinham horário marcado para ser vistos e livros tinham o momento certo para ser lidos. O broadcast e a televisão não são um evento especial para o qual o espectador se prepara e destina um horário certo. Ele simplesmente liga o televisor e a sequência de imagens está lá, a qualquer hora.

Na década de 1970, quando Williams teorizou sobre o fluxo, antes do surgimento da MTV nos Estados Unidos, a televisão agregava novas particularidades que iriam se consolidar durante a década de 1980: o controle remoto e o zapping, a programação 24 horas por dia, o aumento do número de canais e a televisão segmentada por assinatura - consequentemente, o aumento de reprises e a diminuição de força do programa inédito. Tais inovações levaram-no a crer que a percepção do espectador televisivo se faz pelo fluxo, e não por unidades distintas e separadas, os programas, justamente pelo enevoamento das fronteiras entre eles e seus intervalos comerciais. Didático, Williams divide em três os tipos de fluxo.

O primeiro seria o fluxo que inclui determinado tipo de programa, por exemplo, vespertino e que se torna convencional como "programação" ou "listing". Ou seja, é o período da grade que tem uma programação similar. Um exemplo são os programas destinados às donas de casa nos horários matutinos em diversos canais. Desse modo, haveria um eixo perpendicular aos canais na grade, apresentando uma similaridade temática e estética que sobreviveria como fluxo até mesmo fazendo uso do controle remoto. $O$ segundo fluxo e mais evidente

${ }^{5}$ Para fins metodológicos, considera-se aqui que comerciais e vinhetas também são programas televisivos. seria o da atual sucessão de itens, que inclui, além do programa, os programas ${ }^{5}$ do intervalo. Ou seja, parte da exibição ininterrupta de segmentos na grade, programas ou comerciais, especialmente quando um faz referência ao outro. É importante porque é centrado na experiência da televisão e no processo da relativa unificação das partes em um fluxo. Por fim, o fluxo detalhado, que abrange o movimento geral da atual sucessão de palavras e imagens - entre o texto dos 
diversos programas que se assemelham, especialmente o fechamento de blocos e comerciais -, a combinação e fusão entre elas, com o processo de movimento e interação pela sequência e fluxo.

As teorias de fluxo televisivo propostas por Williams chamaram a atenção para outra televisão nascente, que configurava uma nova relação de espectatorialidade com o meio. Por outro lado, essas teorias resultaram em uma leitura, muitas vezes equivocada, assumida por muitos ainda hoje, de que somente por meio do fluxo seria possível analisar televisão. Na prática, seria dizer que não se poderia analisar a individualidade de um programa, e que este teria de ser investigado sem nunca esquecer o fluxo no qual estava inserido.

Ainda que as ideias de Williams tenham sido extremamente aceitas, inúmeros teóricos da televisão se opuseram à sobreposição do fluxo sobre o programa para a análise deste último. Em Visible fictions (1992), John Ellis faz uma análise do cinema e da televisão. No capítulo em que começa a tratar de televisão, "Broadcast TV as cultural form", o autor aparentemente faz uma ironia com o nome do livro de Williams e critica a ideia de fluxo. Para Ellis (1992: 117), há muitos programas que seguem outro modelo, o do segmento, os quais não têm conexão necessária entre si. O fluxo de Williams reuniria itens separados, colocando-os na mesma experiência de espectatorialidade, mas o fluxo não os organizaria criando um sentido global. 0 problema apontado por Ellis na teoria de fluxo é que, quando Williams fala que o fluxo é composto por itens, Ellis lembra que itens são ainda textos separados e estariam longe, por exemplo, de se assemelharem a um filme de cinema.

Ou seja, ainda que se possa pensar, utilizando as palavras de Walter Clark, que existe um "gênio de plantão" que programa a grade nas emissoras e ainda que os canais de televisão reúnam em sua grade programas condizentes com a visão de mundo dos donos do canal, os itens ou segmentos que compõem o fluxo não apresentam necessariamente uma conexão entre si. Arlindo Machado e Marta Lucía Vélez também demonstraram as limitações do conceito de fluxo proposto por Raymond Williams:

É preciso considerar finalmente - e esse nos parece o ponto mais importante - que a ideia de programa leva ainda, sobre a ideia de fluxo, a vantagem de permitir uma abordagem seletiva e qualitativa. O conceito de fluxo empastela toda a produção televisiva num caldo homogêneo e amorfo, enquanto o de programa permite nitidamente distinguir diferenças ou perceber qualidades que despontam sobre o fundo da mesmice. (MACHADO; VÉLEZ, 2007: 5)

Assumindo as críticas de John Ellis e Arlindo Machado ao conceito de fluxo, cabe refletir sobre as possibilidades de segmentação possíveis. Ela seria externa, em que o fluxo seria composto pela variedade dos programas em uma mesma grade ou canal; interna, em que se observam unidades distintas dentro dos próprios programas, que reúnem segmentos para atribuir sentido (novelas, telejornais, programas de auditório, programas infantis); e, por fim, transversal, em que, por meio do zapping, pode-se fazer uma "leitura" de imagens por diversos canais. 0 que está em jogo nessas possibilidades é atribuir sentido a esses fluxos distintos.

Tais possiblidades soam incompletas para justificar o fluxo, pela dificuldade em atribuir sentido único a segmentos distintos dentro de um canal, o que é mais viável dentro de programas, em que a diferença entre seus eventuais segmentos internos ainda viabiliza uma possibilidade de sentido único. Desse modo, talvez o lugar em que se possa buscar uma grande proximidade com o fluxo é nos canais de narrowcast, ou por assinatura, que, por se basearem na demanda do espectador, se conformam tematicamente, cada qual orientado por determinado gênero ou categoria de programa para atender a um nicho específico de público. Além disso, nesses canais, são constantes as reprises ao longo do dia, seja de programas, 
reportagens ou imagens. Desse modo, por esses canais se apresentarem muitas vezes como uma enunciação reiterada em suas temáticas, narrativas, estéticas e imagens, estaríamos mais perto da proposta de fluxo em um canal segmentado que tematize, por exemplo, esportes, notícias, reality shows ou que contemple formatos de programas muito demarcados, do que nos canais abertos em que a programação, generalista, apresenta distinções maiores entre os programas e segmentos. É nessa discussão que se deve retornar à experiência da MTV.

O canal segmentado se aproximaria de um fluxo mais do que o canal generalista, por serem os programas com a mesma temática e aparentarem ser repetitivos, com muitas reprises de programas. Ainda assim, é importante salientar que continuam com segmentos distintos. Contudo, esses segmentos são muito semelhantes entre si e se repetem. A MTV, da maneira como foi configurada na década de 1980 nos Estados Unidos e na de 1990 no Brasil, tinha toda a programação composta por videoclipes e vinhetas que são muito semelhantes entre si nas estéticas variadas, na duração, na montagem, na música. Além disso, ao se considerar que os videoclipes são peças promocionais de artistas e bandas musicais, significa que eles se assemelham em parte aos comerciais. Se a programação de um canal específico, como a MTV, é composta principalmente por peças promocionais/comerciais e vinhetas, todas tematizando o universo musical e o gênero do rock n'roll, poder-se-ia refletir sobre duas particularidades importantes do canal para essa discussão. A MTV, por seus segmentos, por ser um canal temático bem-recortado, ao menos em seu início ligado ao gênero do rock e pop, é um dos canais que mais se aproximaram da proposta de fluxo de Raymond Williams. Ou seja, o espectador pode perceber o canal como um fluxo, ainda que ele mantenha as distinções entre seus segmentos. O que difere a MTV de um canal de televisão tradicional é que este tem seus segmentos, ou seja, seus programas, mais claramente delimitados. Por outro lado, a MTV parece também

${ }^{6}$ Para mais detalhes, ver Kozloff (1992). evidenciar o que Sarah Kozloff ${ }^{6}$ apontou, que os comerciais seriam os verdadeiros programas televisivos, o que é confirmado por Zico Goes:

Se dizia [sic] à época que o conteúdo mesmo da MTV não eram os videoclipes, eram os VJs e os promos, principalmente. E o break comercial eram os clipes, porque os clipes nada mais eram, na época, do que releases dos CDs, enfim, dos álbuns dos artistas da época.. Então tinha essa brincadeira no começo. (GOES, 2013)

Se essa é uma característica tanto da MTV norte-americana quanto de suas franqueadas do resto do mundo, qual é a diferença da MTV Brasil nesse contexto? O fato de o Brasil, conforme mencionado anteriormente, não conhecer até então a lógica da TV segmentada e de a MTV Brasil, que é um canal segmentado, entrar na grade aberta do país reforça sua diferença com relação aos outros canais e evidencia uma nova forma de espectatorialidade na televisão daquele período que compreendeu a década de 1990. Nesse sentido, poder-se-ia dizer que a MTV, em seus momentos iniciais, em que privilegiava a exibição de videoclipes e vinhetas, seria não apenas uma music television, mas, considerando as possibilidades de fluxo apontadas por Williams, a emissora que mais se aproximaria de uma flow television?

\section{O ocaso da flow television}

Sintomaticamente, as mesmas características que apontaram a MTV e especialmente a MTV Brasil como o canal que talvez melhor se aproximasse das proposições iniciais de Williams com relação ao fluxo televisivo serviram para evidenciar seu próprio fracasso.

O que aconteceu com a MTV norte-americana e a brasileira, de maneiras diferentes, foi que em ambas o videoclipe e as vinhetas perderam espaço para programas de gêneros distintos que demonstravam claramente o caminho para uma programação mais generalista e, consequentemente, mais diversificada. Nos Estados Unidos, 
foram criados outros canais que absorvessem videoclipes e vinhetas, conforme dito anteriormente, dando espaço para que o canal principal diversificasse sua programação e se aproximasse, com isso, da programação de outros canais. A MTV Brasil, por sua vez, não se desdobrou em outros canais, apesar de, em determinado momento, fosse esta a intenção do Grupo Abril. Sem um canal para onde direcionar videoclipes e vinhetas, os primeiros se deslocaram para a internet, em um site da própria MTV, colocando, de certa maneira, o videoclipe em uma estrutura de vídeo sob demanda antes mesmo das outras emissoras. Assim, a MTV Brasil passou a dar mais espaço, especialmente na década de 2000, a outros formatos, programas e gêneros: reality shows, política, sexo, humor, programas de auditório. A música deixava de priorizar o rock e passou a agregar o pop e as músicas brasileiras de apelo mais popular, como o axé, o pagode e o funk.

Pode-se dizer que o que influenciou as mudanças da MTV Brasil foram particularidades muito próprias, em especial o fato de ser um canal segmentado no espectro aberto. Se a MTV surge como um canal, tanto nos Estados Unidos quanto no Brasil, em um momento que, para alguns autores, acontecia a transição da paleo para a neotelevisão, a MTV Brasil representa essa permeabilidade de um "momento" televisivo no outro. Ou seja, enquanto a MTV matriz segmentou ainda mais o canal em outros canais no narrowcast, a MTV Brasil foi se tornando cada vez mais um canal generalista, ou seja, um canal aberto no espectro aberto, tomando, de certa maneira, um sentido oposto, porém complementar, à matriz. A MTV original, mesmo sendo um canal no espectro segmentado, também aproximou sua grade e programação do broadcast e dos canais mais generalistas. Observa-se também, nesse contexto, outro movimento que corrobora as relações entre paleo e neotelevisão. Enquanto muitos canais generalistas tradicionais no Brasil, com características tributárias da paleotelevisão, de acordo com os conceitos teóricos desenvolvidos por Umberto Eco (1984) e desenvolvidos em seguida por Francesco Casetti e Roger Odin (1990), absorveram particularidades da neotelevisão - a quebra de tabus com sexo e dinheiro, a presença do povo como personagem, a autorreferencialidade das metaimagens, o fim de uma relação hierárquica entre apresentador e espectador, a diminuição do caráter pedagógico da televisão e a presença do visual suplantando o texto - , aconteceu o inverso com a MTV Brasil: ela passou a dar mais atenção ao texto em detrimento da imagem - tomando seu início como referencial - e assumiu muitas vezes um caráter pedagógico diante do jovem, com os programas que discutem política ou sexo. Isso aconteceu com inúmeros programas que não tinham qualquer relação com o videoclipe ou a música, mas que ainda assim o canal passou a produzir e a exibir, porque eram jovens. De acordo com Zico Goes, o videoclipe sozinho não sustentava a audiência, o que os levou a fazer programas.

Assim, a MTV Brasil, que nasce neotelevisão, com o tempo agrega e caminha para características paleotelevisivas, abandonando algumas particularidades caras a suas origens. E o posicionamento do canal em um espectro aberto, junto com outros canais não segmentados, possivelmente reforçou esse caminho da MTV Brasil, da flow television para a televisão generalista. A modificação da MTV Brasil para a TV generalista foi tão forte que a mudança de rumos para o popular e para a diversidade na programação fez com que parte de seus espectadores e críticos ficasse insatisfeita. Em matéria no jornal Folha de S.Paulo, em 2006, um dos ex-diretores de programação da MTV, Andre Vaisman, chegou a dizer que a emissora teria virado, em função do excesso de programas de auditório, um "SBT para jovens" (ALENCAR, 2006), referindo-se aos programas do canal de Sílvio Santos. A despeito de uma crítica elitista e um tanto preconceituosa, em termos de percurso como canal, por um lado não poderiam estar mais certos.

A programação adotada com os anos pela MTV Brasil também não deixa de confirmar o entendimento de que paleo e neotelevisão não são momentos estanques que definem diferentes modalidades televisivas sobre uma linha 
${ }^{7}$ Programa exibido entre 1999 e 2002, com pausa entre 2000 e 2001.

${ }^{8}$ Programa exibido entre 1999 e 2001.

${ }^{9}$ Programa exibido a partir de 2009 e ainda na grade da Rede Globo de Televisão.

${ }^{10}$ Programa exibido entre 2000 e 2003. cronológica, mas modalidades que coexistem simultaneamente. Ainda que a MTV Brasil tenha migrado para as características de uma televisão clássica, com programas diversificados que distanciavam seu conteúdo da possibilidade de ser entendida como um canal em fluxo, seus programas mostravam, contudo, que, apesar de se render a formatos populares e antigos, como os programas de auditório, ela nunca deixou totalmente a subversão característica da televisão moderna, da neotelevisão, espaço no qual nasceu de modo radical.

Inúmeros programas da MTV Brasil reforçavam esse caráter ambíguo. Os Piores Clipes do $\mathrm{Mundo}^{7}$, apresentado por Marcos Mion, absorvia a precariedade como estética e evidenciava o caráter de representação da televisão trabalhando com a metalinguagem. Em outro viés, o Erótica $M T V^{8}$, apresentado por Jairo Bouer e a modelo e atriz Babi Xavier, discutia sexo abertamente entre os jovens, respondendo a perguntas que dificilmente seriam possíveis na TV aberta. Vale ressaltar que demorou 10 anos para que a Rede Globo tivesse um programa com alguma semelhança do ponto de vista de quebra de tabus com a temática do sexo, que é o Amor \& Sexo ${ }^{9}$, apresentado pela modelo Fernanda Lima. A escolha da Globo pela apresentadora para esse programa não parece ter sido aleatória: Fernanda Lima era a apresentadora do programa Fica Comigo ${ }^{10}$, uma releitura da MTV do clássico programa Namoro na TV, do SBT, em que casais se conhecem por meio do programa e começam ou não o relacionamento ao vivo. Sobre esse programa cabe um exemplo pertinente à discussão que ora se segue: em agosto de 2000, a MTV teve alto índice de audiência com o primeiro - e único - Fica Comigo Gay, em que os protagonistas, dois homens, deram o primeiro e mais demorado beijo gay masculino na televisão aberta brasileira. Mesmo passados quatorze anos do episódio, dificilmente a apresentadora poderá repetir o feito na atração que comanda hoje na emissora líder de audiência da TV aberta.

Esses e outros programas exibidos pela MTV Brasil evidenciam como a emissora caminhou para formatos televisivos antigos, mas sem abrir mão do caráter moderno na constituição interna de seus programas - no sentido neotelevisivo. Tais programas, ainda que também conferissem identidade ao canal, tinham uma variedade de formatos e estruturas muito distintos, sobretudo em comparação ao início da programação do canal, composto apenas por videoclipes, e que evidencia uma flow television mais contundente, especialmente em meio ao line-up generalista.

Desse modo, pode-se dizer que a MTV Brasil teve um outro fim anterior àquele do ano de 2013 e ainda mais importante. Foi quando ela, ao agregar uma série de programas, aproximando-se de uma televisão generalista, deixou de ser uma flow television dentro do próprio broadcast. As sucessivas mudanças em busca do público migrante da MTV talvez tenham quebrado constantemente seus registros de enunciação, o que foi, aos poucos, eliminando o seu caráter mais contundente de flow television. Com isso o caráter moderno desse canal na grade da televisão brasileira e, por que não dizer, revolucionário, começa a ser minimizado até desaparecer quase por completo. A extinção da MTV Brasil, no fim do ano de 2013, é o término não apenas de um canal, mas de uma proposta de televisão que elucida questões caras à espectatorialidade, à teoria da televisão e à história da TV brasileira.

\section{Considerações finais}

Zico Goes afirma que a MTV Brasil se transformou com o tempo porque precisava se modificar constantemente em função de um público que também mudava, um público jovem que não se pode fidelizar, pois envelhece e deixa de ver o canal, cedendo o lugar a uma nova geração com novos interesses: "daí a necessidade de mudança, novas caras, novos programas e assim por diante" (GOES, 2013). Ainda que não se possa generalizar o público jovem com uma só identidade ou como algo fechado, o que a MTV Brasil parece sempre ter feito foi perceber a dimensão plural do jovem deixando de o mitificar, como talvez até tenha feito no começo de suas transmissões, para depois tentar se adaptar às suas transformações 
constantes. Por isso deixou de ser só rock e passou a ser também pop, para depois agregar também o popular, para o incômodo de muitos dos que, naquela ocasião, já não eram mais tão jovens ou não eram sua faixa preferencial de espectadores.

De certo modo, a televisão também tem a mesma dinâmica do público jovem. Ela agrega funcionalidades com a tecnologia, absorve demandas sociais, agrega discursos em constante mudança. A MTV foi uma bomba experimental que, pelas circunstâncias, no Brasil ganhou ainda mais intensidade. Ela mudou não apenas porque seu espectador se modifica o tempo todo, mas porque o próprio meio se transforma. Os modos de espectatorialidade também se modificam constantemente. Se havia uma espectatorialidade neotelevisiva, de contato, no início da MTV, que subvertia a televisão clássica, ficou claro que um canal não se sustenta apenas com uma espectatorialidade menos textual e mais clássica. Mesmo uma TV como a MTV e suas distintas gerações de espectadores demandam contratos com os diferentes gêneros, com os formatos e programas, vivenciando também uma experiência paleotelevisiva, de contrato entre o público e cada programa.

Uma televisão não pode ser só fluxo, não pode ser só neotelevisão. O ocaso da MTV Brasil parece comprovar isso, e a MTV atual, que pouco difere da maior parte dos canais segmentados e é calcada na MTV norte-americana, talvez fosse novidade no Brasil de 1990, mas não seria tão radical e experimental como foi a MTV Brasil quando foi implantada. A nova MTV, exibida, agora sim, em seu lugar original, como canal segmentado no narrowcast, não se diferencia nem da MTV norte-americana nem de boa parte dos canais a cabo. $O$ irônico da distinção entre as duas emissoras em suas respectivas épocas é que a MTV Brasil nasceu moderna como neotelevisão, flow TV e como um canal segmentado na televisão brasileira aberta, e por isso revolucionária para a estética, linguagem e teoria da televisão. A MTV Brasil, em seu início e no contexto da época, talvez tenha sido, na história da televisão brasileira, o que o urinol de Duchamp foi para a história da arte.

Por outro lado e ironicamente, a nova MTV nasce quase clássica, talvez com mais características de paleo do que de neotelevisão, demandando, com isso, um contrato menos que o contato que a MTV proporcionava com seu espectador. A nova MTV nasce como um canal generalista na televisão fechada, ou seja, faz o oposto da MTV Brasil. Perde seu diferencial e se perde na quantidade de canais, apenas como mais um. Como afirma Zico Goes na epígrafe deste texto, a ruptura com o modelo anterior foi radical. Mas a mudança da MTV pode ser lida também como algo de novo, na medida que o canal com caráter de segmentado, ao renunciar ao seu modelo de enunciação, subverte as próprias regras da TV temática, tornando-se híbrida: estruturalmente generalista, formalmente moderna em seus programas por manter vários aspectos da neotelevisão, como a quebra de tabus e a autorreferencialidade constante.

E, por fim, talvez caibam algumas perguntas para se pensar a posteriori. Será que o modelo ou os efeitos de uma televisão experimental, moderna, como foi a MTV Brasil, de fato envelheceu, como afirma Goes? Será que eles não conseguiram, enfim, seguir seu público? Qual o espaço da experimentação, onde estariam hoje essas possibilidades ou quem deteria hoje, o papel que coube à MTV Brasil em 1990? Será que ainda seria em um canal de televisão ou essa experimentação, de certo modo já se espalhou por outros espaços? O programa humorístico da Rede Globo Tá no Ar: a TV na TV, criado e apresentado por Marcius Melhem e Marcelo Adnet, este último antigo humorista da MTV Brasil, parece reproduzir muitas dessas inovações dentro do próprio programa: a autorreferencialidade, o zapping e o fluxo. Incensado como um dos programas recentes mais originais na televisão, ele migrou para a internet. Então parece que a experiência da MTV Brasil continua viva em programas específicos, dispersos pela programação no line-up, mas resta saber se esse tipo de experiência ainda se sustenta como canal e, se não, qual o prejuízo dessa ausência para a variedade e as possibilidades de espectatorialidade na televisão. 
Ou por outro lado, em tempos de hipertelevisão, estas estratégias estariam em canais que se utilizem da internete explorem de modo radical o transmídia, ozapping midiático e o vídeo sob demanda que, assim como a MTV Brasil naquele momento, possibilitam hoje, em novo contexto, novas formas de espectatorialidade e, consequentemente, novos modelos e formatos de programas ou possibilidades de transmissão e consumo. É um problema não ter mais uma MTV Brasil para a recepção televisiva, nos antigos moldes, ou ao menos algo que cumpra esse papel de virar a lógica da televisão do avesso, rompendo estruturas e possibilitando uma televisão diferente com novas possibilidades estéticas. Esses novos moldes ainda são necessários, serão ou já estão sendo substituídos por outros modelos? Mais do que isso, será que sobreviveriam ou, assim como a MTV Brasil, necessariamente agregariam outros modelos de televisão para ampliar o seu público e com isso perderiam sua singularidade?

Nesse sentido, cabe pensar se tais experiências televisivas, em função da dinâmica do próprio meio, da transformação do seu público e da sua tecnologia, das suas narrativas e estéticas, bem como a própria modificação da televisão enquanto um bem cultural - em um sentido mais amplo o que se pode chamar de um fenômeno televisão - não impõem limites ao novo, que já nasceria com uma data de validade. $O$ espectador mutante de um meio sempre em movimento talvez revele não apenas o que afirma Zico Goes sobre a MTV Brasil - uma emissora com a necessidade de ser sempre outra coisa - mas a própria condição inerente à televisão enquanto meio. O novo é necessário e bem vindo, mas ele é rapidamente absorvido e se junta às antigas possibilidades de televisão, que continuam sendo experienciadas, demandadas e consumidas, sejam através dos mecanismos tradicionais ou de tecnologias que possibilitem uma renovação na espectatorialidade. Talvez o ocaso da MTV Brasil, enquanto canal, seja a confirmação de sua importância no momento que suas contribuições quase revolucionárias se espalharam pela televisão de diferentes maneiras, revalidando suas experiências e seu poder de transformação. Apesar de aparentemente ainda não haver uma resposta clara e definidora para essas indagações, elas apontam, sobretudo, para uma dinâmica própria e sempre cinética da televisão como técnica, fluxo, espectatorialidade e modos de recepção.

\section{Referências Bibliográficas}

ALENCAR, Juliana. PlayTV passa MTV em audiência e disputa público jovem. Folha de S.Paulo, Caderno llustrada, 9 ago. 2006. Disponível em: <http://www1.folha. uol.com.br/folha/ilustrada/ult90u63245.shtml>. Acesso em: 9 jan. 2014.

CALDWELL, John Thornton. Televisuality: style, crisis, and authority in American Television. New Jersey: Rutgers, 1995.

CASETTI, Francesco; ODIN, Roger. De la paléo- à la néo-télèvision. In: Communications: Télévision mutations. no 51, 1990. p. 9-26.

ECO, Umberto. Viagem na irrealidade cotidiana. Rio de Janeiro: Nova Fronteira, 1984.

ELLIS, John. Visible fictions: cinema, television, video. Londres: Routledge, 1992.

GOES, Zico; THUNDERBIRD; LAZAROTTO, Cuca; SUTTER, Bruno. MTV: VJs, histórias e transgressão. In: FESTIVAL INTERNACIONAL DE TELEVISÃO, 2013, Rio de Janeiro. Linguagem e experimentação. Rio de Janeiro: Oi Futuro, 14 nov. 2013. Mesaredonda.

KAPLAN, E. Ann. Rocking around the clock: music television, postmodernism \& consumer culture. Nova York: Methuen, 1987. 
KOZLOFF, Sarah. Narrative theory and television. In: ALLEN, Robert C. (Ed.). Channels of discourse, reassembled. Carolina do Norte: North Carolina Press, 1992.

LUSVARGHI, Luiza. De MTV a EMETEVE: pós-modernidade e cultura mcworld na televisão brasileira. São Paulo: Editora de Cultura, 2007.

MACHADO, Arlindo; VÉLEZ, Marta Lucía. Questões metodológicas relacionadas com a televisão. E-compós: Revista da Associação Nacional dos Programas de Pósgraduação em Comunicação, n. 8, abr. 2007.

MUANIS, Felipe. Metaimagens na televisão e vanguardas: as vinhetas da Rede Globo e MTV. In: ENCONTRO XX COMPÓS. Anais... Porto Alegre, 2011.

PEDROSO, Maria Goretti; MARTINS, Rosana (Org.). Admirável mundo MTV Brasil. São Paulo: Saraiva, 2006.

WILLIAMS, Raymond. Television as cultural form. Londres: Wesleyan, 1992. 